\title{
Intracellular chloride concentration of the mouse vomeronasal neuron
}

\author{
SangSeong Kim ${ }^{1,2^{*}}$, Limei Ma' ${ }^{1}$ Jay Unruh'1, Sean McKinney ${ }^{1}$ and C. Ron $\mathrm{Yu}^{1,3^{*}}$
}

\begin{abstract}
Background: The vomeronasal organ (VNO) is specialized in detecting pheromone and heterospecific cues in the environment. Recent studies demonstrate the involvement of multiple ion channels in VNO signal transduction, including the calcium-activated chloride channels (CACCs). Opening of CACCS appears to result in activation of VNO neuron through outflow of $\mathrm{Cl}^{-}$ions. However, the intracellular $\mathrm{Cl}^{-}$concentration remains undetermined.

Results: We used the chloride ion quenching dye, MQAE, to measure the intracellular $\mathrm{Cl}^{-}$concentration of VNO neuron in live $\mathrm{VNO}$ slices. The resting $\mathrm{Cl}^{-}$concentration in the $\mathrm{VNO}$ neurons is measured at $84.73 \mathrm{mM}$. Urine activation of the VNO neurons causes a drop in $\mathrm{Cl}^{-}$concentration, consistent with the notion of an efflux of $\mathrm{Cl}^{-}$to depolarize the cells. Similar observation is made for VNO neurons from mice with deletion of the transient receptor potential canonical channel 2 (TRPC2), which have a resting $\mathrm{Cl}^{-}$concentrations at $81 \mathrm{mM}$.
\end{abstract}

Conclusions: The VNO neurons rest at high intracellular $\mathrm{Cl}^{-}$concentration, which can lead to depolarization of the cell when chloride channels open. These results also provide additional support of TRPC2-independent pathway of VNO activation.

Keywords: Vomeronasal organ, TRPC2, Pheromones, Calcium activated chloride channel

\section{Background}

Chloride ion plays an important role in controlling cell excitability. $\mathrm{Cl}^{-}$flowing through GABA receptors is generally inhibitory, but in developing brain, high intracellular $\mathrm{Cl}^{-}$concentration allows the efflux of $\mathrm{Cl}^{-}$making it excitatory. Likewise, the mammalian olfactory sensory neurons maintain an intracellular $\mathrm{Cl}^{-}$concentration of $\sim 69 \mathrm{mM}$ [1] or $40-50 \mathrm{mM}$ [2]. Odor stimulation activates the cyclic nucleotide-gated (CNG) channel and results in calcium influx activating calcium-activated chloride channels (CACCs) to depolarize the neurons [3-10].

Recent studies have revealed the involvement of a chloride conductance in VNO activation. In VNO neuron, urinary stimulus appears to activate CACC currents. The

\footnotetext{
*Correspondence: talpiot@hanyang.ac.kr; cry@stowers.org

1 Stowers Institute for Medical Research, 1000 East 50th Street, Kansas City, MO 64110, USA

${ }^{2}$ Department of Pharmacy, Institute of Pharmaceutical Science and Technology, Hanyang University, Seoul, Gyeonggi-do, Republic of Korea

Full list of author information is available at the end of the article
}

chloride conductance is carried by TMEM16A/anoctamin 1 [11] and can be activated independently of the TRPC2 channel, therefore constitutes a parallel signal transduction pathway [12-14]. The level of intracellular $\mathrm{Cl}^{-}$is critical in determining the direction of current flow. With high $\left[\mathrm{Cl}^{-}\right]_{\text {in }}$, efflux of $\mathrm{Cl}^{-}$would result in an inward current to depolarize the cells. Conversely, at low $\left[\mathrm{Cl}^{-}\right]_{\text {in }}$, the ions may not flow across the cell membrane or flow intracellularly leading to an outward current to hyperpolarize the cells. In slice and single cell recordings [12-14], activation of CACC currents appears to depolarize the VNO neurons, suggesting that these cells maintain a high intracellular $\mathrm{Cl}^{-}$concentration. However, the concentration of $\mathrm{Cl}^{-}$in $\mathrm{VNO}$ neurons has not been determined.

We sought to determine the intracellular $\mathrm{Cl}^{-}$concentration of VNO neurons in live slice preparations. In the olfactory neurons, intracellular ion concentrations were first determined by energy-dispersive X-ray microanalysis in cryosections of the rat olfactory epithelium [1]. This method required highly specialized equipment that 
is not easily accessible. Kaneko and colleagues measured intracellular $\mathrm{Cl}^{-}$concentration in the olfactory neuron by using $N$-[ethoxycarbonylmethyl]-6-methoxy-quinolinium bromide (MQAE) as a fluorescent chloride ion indicator $[2,15]$. In this study we adopt this method to measure intracellular $\mathrm{Cl}^{-}$concentration in the mouse VNO neurons.

\section{Results and discussion}

\section{Intracellular $\mathrm{Cl}^{-}$concentration in the VNO neurons}

MQAE is used as a chloride fluorescent indicator to determine the intracellular $\mathrm{Cl}^{-}$concentration because of its collisional quenching property. High $\mathrm{Cl}^{-}$concentration quenches its fluorescent signal. It has been successfully used to monitor the intracellular $\mathrm{Cl}^{-}$concentrations of olfactory neurons, the dorsal roots ganglion cells, salivary glands as well as brain slices $[2,15,16,17,18]$. We prepared VNO slice at $100 \mu \mathrm{m}$ thickness to preserve the intact neuronal structure including the dendrite. Incubating VNO slice with MQAE for $30 \mathrm{~min}$ resulted in robust fluorescence in the VNO neurons. After loading we measured the fluorescent signals in the VNO neurons incubated in Tyrode solution before and after urine application (Fig. 1). Fluorescent signals in VNO slice noticeably increased during urine application, indicating a reduction of intracellular $\mathrm{Cl}^{-}$. The elevation of fluorescent signals lasted the entire duration of urine application. This is consistent with previous observation that the VNO neurons exhibit non-adaptive responses [19, 20]. Over the course of urine application there is no change in background fluorescence, indicating that the changes were not from signals of urine application (Fig. 1B). On average there was a $12 \%$ increase in fluorescence $\left(\mathrm{P}<10^{-14} ; \mathrm{n}=11\right)$. This observation is consistent with previous observation that urine induces efflux of $\mathrm{Cl}^{-}$ from VNO neurons [12-14].

To estimate the intracellular $\mathrm{Cl}^{-}$in slice preparation, we measured the fluorescent signals in a series of standard $\mathrm{Cl}^{-}$solutions. The neurons were permeabilized with ionophores and incubated with the standard solutions. $\mathrm{Cl}^{-}$homeostasis is maintained by chloride co-transporters including $\mathrm{Na}-\mathrm{K}-\mathrm{Cl}$ co-transporter $[21,22]$ and $\mathrm{K}-\mathrm{Cl}$ co-transporter [23]. The homeostasis mechanism may skew the results when the standard solutions dramatically alter the intracellular salt balance. Thus, in addition to chloride ionophore 1 , we used the $\mathrm{Cl}^{-} / \mathrm{OH}^{-}$ionophore tributyltin to remove transmembrane $\mathrm{H}^{+} / \mathrm{OH}^{-}$ gradients. We also include nigericin, an ionophore for
A

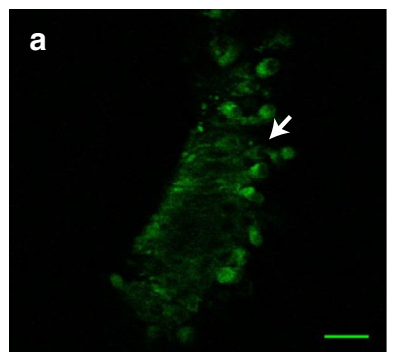

Tyrode solution

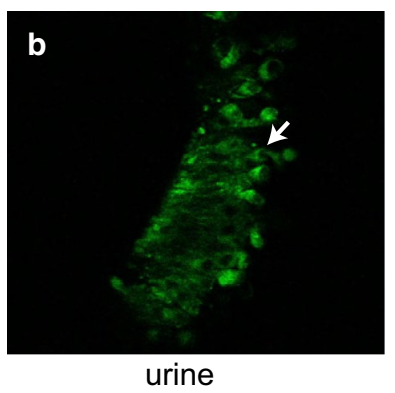

B
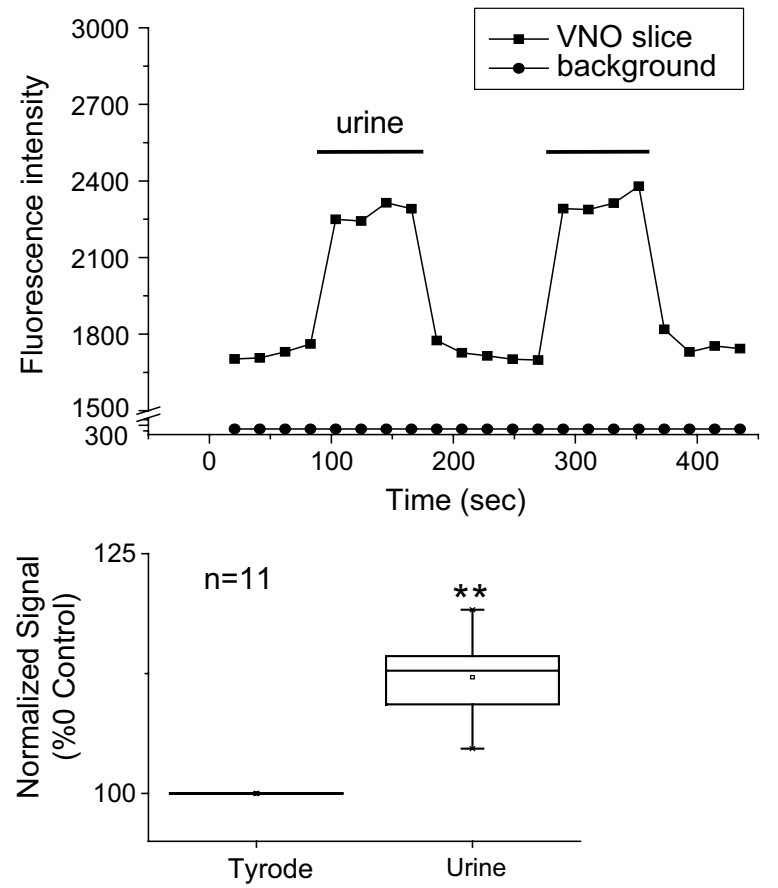

Fig. 1 Urine induced change in MQAE fluorescence in VNO slices. A Image of VNO slice in Tyrode solution ( $a$ ) and in response to urine stimulation (b). Scale bar is $25 \mu \mathrm{m}$. B Quantitative measurement of fluorescence signal during urine application for the cell indicated by the arrows. Square indicates VNO slice image and circle for background change. C Box plot indicates relative fluorescence changes in response to urine (1.12 \pm 0.01 , $\mathrm{n}=11$ ). Box plots show the mean (central point), median (central horizontal line in the box), maximal and minimal values (short horizontal lines), 99 and $1 \%$ range (crosses at both ends of the box), 5-95\% percentile range (whiskers) and 25-75\% range (box). **P < 0.05, Student's t test 
$\mathrm{H}^{+}, \mathrm{K}^{+}$and $\mathrm{Cl}^{-}$, to remove the contribution of cations in resetting $\mathrm{Cl}^{-}$gradient. A previous study has shown that these ionophores dissipate $\mathrm{Cl}^{-}$gradients across the plasma membrane [24]. By abolishing $\mathrm{Cl}^{-}$gradient, the intracellular $\mathrm{Cl}^{-}$concentration could be equilibrated with the extracellular $\mathrm{Cl}^{-}$.

Following measurements before and after urine application without ionophores, we measured MQAE fluorescence by incubating the VNO slices with standard solutions containing the ionophore cocktail. MQAE fluorescent intensity was high at low $\left[\mathrm{Cl}^{-}\right]$and the signal was quenched at high $\left[\mathrm{Cl}^{-}\right]$(Fig. 2a). Changing external $\left[\mathrm{Cl}^{-}\right]$ led to quick changes of intracellular fluorescent signals in the slices. We performed repeated imaging using 15 and $150 \mathrm{mM}$ standard solutions over a period of $4 \mathrm{~min}$. The fluorescent intensity at $15 \mathrm{mM}\left[\mathrm{Cl}^{-}\right]$reached the same levels during three applications (Fig. 2b). There was no bleaching effect as observed in previous studies [2]. The difference may be explained by increased sensitivity of a new generation of confocal microscope, which required less laser power to excite the fluorophores.

We applied standard solutions containing 15, 45, 60, 90 or $150 \mathrm{mM} \mathrm{Cl}^{-}$and measured fluorescent intensities. All measurements from the same cell were normalized to the highest fluorescent intensity, measured with $15 \mathrm{mM}$ standard chloride solution (Fig. 2c). The data were fit with the Stern-Volmer equation with linear regression. We used fluorescent signals measured at rest and during urine stimulation to extrapolate $\left[\mathrm{Cl}^{-}\right]_{\text {in }}$ using the standard curve. The intracellular $\mathrm{Cl}^{-}$concentration was determined to be $84.73 \pm 2.65 \mathrm{mM}$ (Fig. 2c; mean $\pm \mathrm{SD}$ ) in tyrode solution. Urine-activation caused detectable increase in fluorescence, indicating a drop in intracellular $\mathrm{Cl}^{-}$concentration resulting from the efflux of $\mathrm{Cl}^{-}$ions (Fig. 1). With the same method the intracellular $\mathrm{Cl}^{-}$concentration in urine presence was calculated as $59.5 \pm 1.54 \mathrm{mM}$, which was $25.23 \mathrm{mM}$ reduction from resting condition (Fig. $2 \mathrm{c}$ ).

\section{$\mathrm{Cl}^{-}$concentration of VNO neuron in TRPC2-/- mice}

In previous studies, we have identified independent pathways in activating the VNO [13, 14]. Although $\mathrm{Ca}^{2+}$ entry through the TRPC2 channels contribute to the activation of $\mathrm{CACC}, \mathrm{Ca}^{2+}$ mobilized from the intracellular store can also activate CACC in the absence of TRPC2. We carried out the same experiments in TRPC2-/- VNO slices to measure $\left[\mathrm{Cl}^{-}\right]_{\text {in }}$. In TRPC2-/- VNO, urine elicited an average of $13 \%$ increase in fluorescence (Fig. 3a, $\mathrm{p}<10^{-6}, \mathrm{n}=6$ ), indicating that urine elicited a drop in $\left[\mathrm{Cl}^{-}\right]_{\text {in }}$. We then calibrated MQAE signals using standard solutions. Linear regression fit from the TRPC2-/- VNO (Fig. 3b) generated similar values of Stern-Volmer constant $\left(8.79 \times 10^{-3} \mathrm{mM}^{-1}\right.$ in wild type and $8.89 \times 10^{-3}$ $\mathrm{mM}^{-1}$ in TRPC2-/-). $\left[\mathrm{Cl}^{-}\right]_{\text {in }}$ measured at resting state was $81.89 \pm 5.59 \mathrm{mM}$, nearly the same as the wildtype (Fig. 3b). Urine application led to an increase in fluorescence, which corresponded to a decrease in $\left[\mathrm{Cl}^{-}\right]_{\text {in }}$

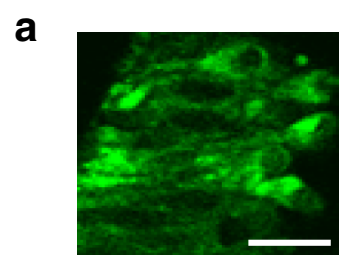

$15 \mathrm{mM}$

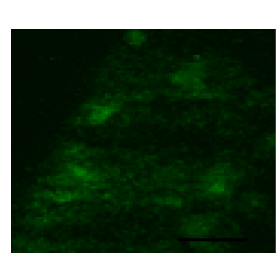

$150 \mathrm{mM}$

b

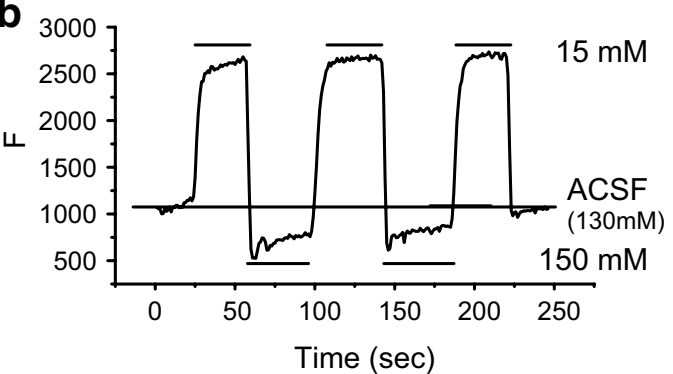

$\mathbf{C}$

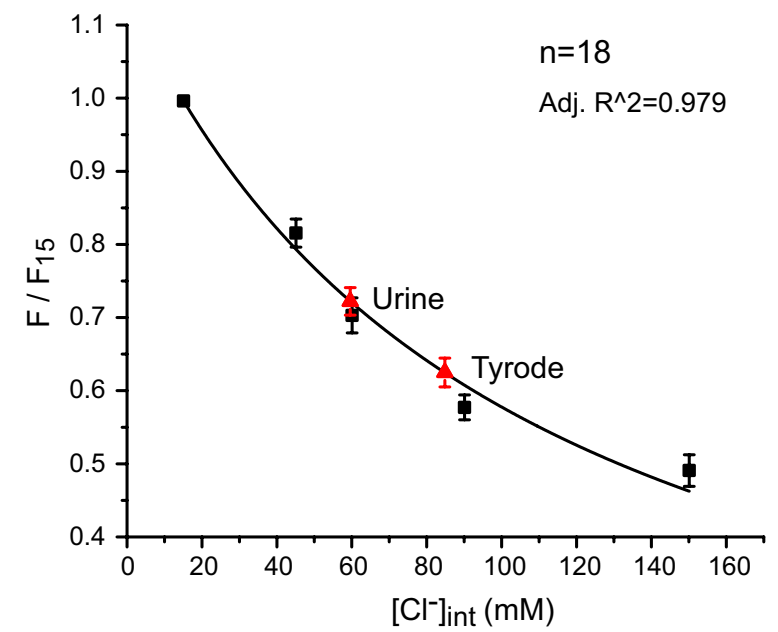

Fig. 2 Measurement of intracellular chloride concentration in VNO neuron. a Fluorescence signal of a VNO slice loaded with MQAE dye and incubated in ionophore cocktail in $15 \mathrm{mM}$ (left) and $150 \mathrm{mM}$ (right) standard solutions. Scale bar is 10 um. b Repeated calibration using the two standard solutions indicates no obvious bleaching. Fluorescent intensity (arbitrary unit) is plotted over time. Top three bars indicate incubation with 15 mM solution and bottom two bars indicate incubation with $150 \mathrm{mM}$ solution. ACSF is used before and after the calibration. c Stern-Volmer equation fit (black lines) to fluorescent signals using standard intracellular chloride concentration (black squares). Average intensities of MQAE fluorescence of VNO neurons at rest (Tyrode) and during urine application are extrapolated to obtain $\left[\mathrm{Cl}^{-}\right]_{\text {in }}$. Data is shown as mean \pm s.e.m 

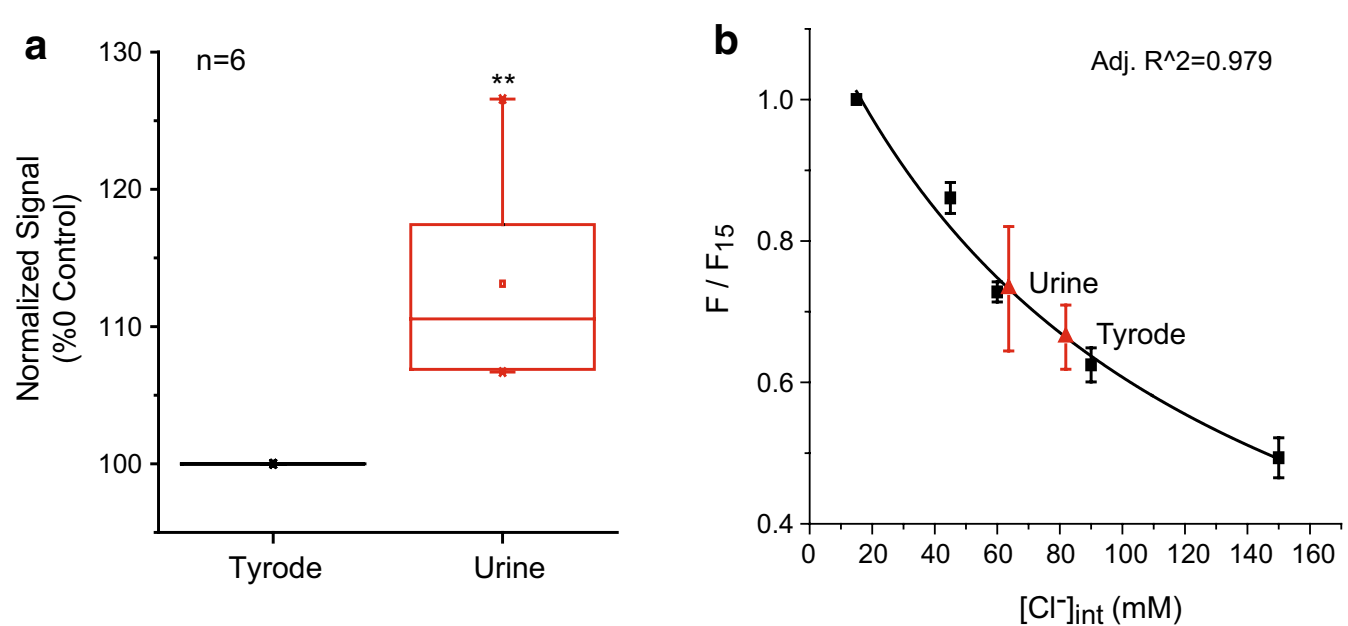

Fig. 3 Measurement of intracellular chloride concentration in TRPC2 mutant VNO neuron. a Box plot indicates the relative fluorescence level change in response to urine application $(1.13 \pm 0.03, n=6)$. b Stern-Volmer equation fit (black line) to fluorescent signals using standard intracellular chloride concentration (black squares) yield Ksv $=8.89 \times 10^{-3} \mathrm{mM}^{-1}(\mathrm{n}=6)$. MQAE fluorescence of VNO neurons at rest (Tyrode) and during urine application are extrapolated to determine $[\mathrm{Cl}]_{\text {int }}$ (red triangles). Box plots show the mean (central point), median (central horizontal line in the box), maximal and minimal values (short horizontal lines), 99 and $1 \%$ range (crosses at both ends of the box), 5-95\% percentile range (whiskers) and $25-75 \%$ range (box). ${ }^{* *} \mathrm{P}<0.05$, student's t test. Data are shown as mean \pm s.e.m

to $63.65 \pm 7.65 \mathrm{mM}$. The concentration reduction was 18.24 mM. The similarity of measured $\left[\mathrm{Cl}^{-}\right]_{\text {in }}$ between wildtype and TRPC2-/- samples is consistent with our previous finding of a TRPC2 independent pathway in activating the chloride conductance $[13,14]$.

\section{Conclusions}

The vomeronasal organ is involved in detection of pheromone cues, which are contained in bodily fluids and excretions. Pheromone-containing fluids, including urine, contain varying salt concentrations that may affect pheromone detection. The vomeronasal organ appears to have evolved specific mechanisms in mitigating the impact by the large variation of ionic concentrations. For example, the supporting cells have specialized ion conductance for $\mathrm{K}^{+}$and $\mathrm{Cl}^{-}$[25]. Recent studies have shown that the VNO utilizes different signal transduction pathways in parallel to mediate its activation $[12,13,14,26,27,28]$. Existing evidence suggests that CACC is involved in VNO signal transduction [12-14]. The ion channels responsible for $\mathrm{Cl}^{-}$conductance is likely to be anoctomin 1 (TMEM16A) and anotamin 2 (TMEM16B), which have been found to be located in the dendritic knob of the VNO sensory neurons [27]. The latest study show that CACC is abolished in the VNO of mice without TMEM16A [11]. In this study, we determine $\left[\mathrm{Cl}^{-}\right]_{\text {in }}$ for VNO neurons at $84.73 \pm 2.65 \mathrm{mM}$ for wildtype and $81.89 \pm 5.59 \mathrm{mM}$ for TRPC2-/ - mice. The values we obtain are remarkably similar to what is observed in the olfactory sensory neurons $[1,2,15$, 29]. Under conditions in which electrophysiology and imaging experiments are conducted (external $\left[\mathrm{Cl}^{-}\right]$ at $\sim 130 \mathrm{mM}$ ), the reversal potential for $\mathrm{Cl}^{-}$calculated from Nernst Equation is at $-21 \mathrm{mV}$. Because VNO neurons rest at $\sim-50 \mathrm{mV}$, the activation of chloride channels would lead to an outward flow of $\mathrm{Cl}^{-}$, causing depolarization of the neurons. Consistent with the notion that the CACC can be activated independently from TRPC2, urine application elicited changes in fluorescent signals in TRPC $2-/-\mathrm{VNO}$. It is noticeable that the resting $\left[\mathrm{Cl}^{-}\right]_{\text {in }}$ in TRPC2-/- VNO is slightly lower than the wildtype. Moreover, urine induced change of $\left[\mathrm{Cl}^{-}\right]_{\text {in }}$ is slightly smaller in TRPC2-/- than in wild type, although the difference is not statistically significant. This evidence provides further support of parallel pathways of VNO activation. It also indicate that TRPC2 may contribute to regulate basal levels of $\left[\mathrm{Cl}^{-}\right]_{\text {in }}$ and to influx of $\mathrm{Cl}^{-}$. A reduction in $\mathrm{Ca}^{2+}$ influx may reduce $\mathrm{CACC}$ activation.

We note that our measurements are from VNO cell body with intact dendrite. Although we observe concomitant change in fluorescent intensity in the dendrites as the cell bodies, technical challenges of imaging in slice have prevented us from accurately track individual dendritic structure. Because intracellular changes are observed in both dendrites and cell bodies during pheromone stimulation, it is likely that calcium activated channels are present in both compartments. Although TMEM16A and TMEM16B may be concentrated in the dendrite to mediate primary response, the expression of bestrophin 2 may allow $\mathrm{Cl}^{-}$movement in the cell body $[12,28]$. 


\section{Methods \\ Animals}

Pheromone-evoked responses were obtained from a total seven of 2-6 months old mice of the C57BL/6 J strain and one TRPC2-/- mouse of same background. Approximately equal numbers of male and female mice were used. Animals were maintained in the Lab Animal Service Facility of Stowers Institute at 12:12 light cycle, and provided with food and water ad libitum. Experimental protocols were approved by the Institutional Animal Care and Use Committee at Stowers Institute and were in compliance with $\mathrm{NIH}$ Guide for Care and Use of Animals. Urine samples were collected from mature male and female C57BL/6J animals using the freecatch method. Equal volumes of male and female urine were mixed and diluted to 1:100 in Ringer's solution for stimulation.

\section{Slice preparation}

Mice were sacrificed by rapid decapitation after $\mathrm{CO}_{2}$ asphyxiation and the VNOs were dissected out into mouse artificial cerebrospinal fluid (mACSF) that was continuously bubbled with $5 \% \mathrm{CO}_{2} / 95 \% \mathrm{O}_{2}$ and maintained at $4{ }^{\circ} \mathrm{C}$. The tissue was embedded in a gel composed of $4 \%$ low melting point agarose dissolved in mACSF at $37{ }^{\circ} \mathrm{C}$, chilled on ice, mounted on a specimen tray, and secured onto the VF-300 microtome sectioning system (Precisionary Instruments). Tissue samples were sectioned into $100 \mu \mathrm{m}$ slices, which were then transferred to mACSF solution and continuously bubbled with $5 \%$ $\mathrm{CO}_{2} / 95 \% \mathrm{O}_{2}$ at room temperature. The composition of mACSF is (in mM): $\mathrm{NaCl} 125, \mathrm{KCl} 2.5, \mathrm{CaCl}_{2} 2, \mathrm{MgCl}_{2} 1$, $\mathrm{NaHCO}_{3} 25, \mathrm{Na}_{2} \mathrm{HPO}_{4}$ 1.25, Glucose (Dextrose) 10.

\section{Measurement of intracellular $\mathrm{Cl}^{-}$}

VNO slices were incubated with $5 \mathrm{mM} \mathrm{N}$ (ethoxycarbonylmethyl)-6-methoxyquinolinium bromide (MQAE, molecular probes) for $30 \mathrm{~min}$ at room temperature in Tyrode solution before it was transferred to a perfusion chamber for imaging using a Zeiss AxioSkope FS2 microscope with a $40 \times$ water-dipping lens (0.8 N.A; $3.3 \mathrm{~mm}$ working distance). Tyrode solution is composed of (in $\mathrm{mM}$ ): $140 \mathrm{NaCl}, 5 \mathrm{KCl}, 2 \mathrm{CaCl}_{2}, 1 \mathrm{MgCl}_{2}, 10$ glucose, and 10 HEPES, pH 7.2. MQAE was excited with 2-photon $750 \mathrm{~nm}$ laser generated from the Chameleon XR system (Coherent). Z-stack images of the VNO slice were recorded with $3 \mu \mathrm{m}$ step increment for each condition. VNO slices were imaged in Tyrode solution and during urine application.

Urine stimulation and standard solutions are delivered using a perfusion system that has been described previously $[30,31]$. The system is under constant pressure and the switching between different solutions does not affect the flow rate and does not cause mechanical movement of the slices. Following urine application, the slices were treated with a series of standard Tyrode solution containing different predetermined concentrations of $\mathrm{Cl}^{-}$(15, 45, 60, 90 and $150 \mathrm{mM}$ ). The standard solutions were applied together with the ionophore cocktail to calibrate fluorescent signals. The calibration solutions contain the following chemicals: $5 \mu \mathrm{M} \mathrm{Cl}^{-} / \mathrm{OH}^{-}$antiporter tributyltin (Sigma), $3.5 \mu \mathrm{M} \mathrm{K} \mathrm{K}^{+} / \mathrm{H}^{+}$antiporter nigericin (Sigma) and $1.5 \mu \mathrm{M}$ chloride ionophore 1 (GFS chemicals). Calibration solution consisted of (in $\mathrm{mM}$ ) $150 \mathrm{KCl}, 2 \mathrm{CaCl}_{2}$, 10 glucose and 10 HEPES (pH 7.2), with different concentrations of $\mathrm{KCl}$ replaced with equal molar $\mathrm{KNO}_{3}$ to achieve desired extracellular $\mathrm{Cl}^{-}$concentrations. Between applications of each different concentration solutions, the sample was washed with Tyrode solution. During imaging, excitation light with $15 \mathrm{~s}$ interval was applied to prevent from bleaching of MQAE.

Individual images were analyzed to measure the intensity of MQAE in selected region of interest (ROI). In previous studies, we have shown that approximately $30 \%$ of cells in slice preparations respond to urine stimulation [13, 14, 32, 19]. We have selected 11 cells with responses to urine stimulation as ROI to measure the response to urine. Additional 7 cells are also selected to measure basal level of $\left[\mathrm{Cl}^{-}\right]$. Because it is difficult to assign the dendritic knob to a specific cell in slice preparations, we only focused on the cell bodies. All analyses were performed off-line. Individual cells in the VNO slices may shift out of focus. To solve this problem, we took Z-stacks of the slice and track individual cells in different Z-plane. Cells with intact morphology that can be discerned during the entire imaging process were used for intensity analysis. ROI of 18 neurons from 7 different slices were selected for analyses. In case of TRPC2-/- mice imaging, a single slice was used. Intensity values measured in each calibration solution were normalized to that of the initial $15 \mathrm{mM} \mathrm{Cl}^{-}$standard solution within individual VNO slices. The averaged data points were fitted using the Stern-Volmer equation [15]:

$$
F_{a}=\frac{F_{0}}{1+K_{q}\left[\mathrm{Cl}^{-}\right]_{i n}}
$$

where $\mathrm{F}_{\mathrm{a}}$ stands for intensity at a given $\mathrm{Cl}^{-}$concentration, $\mathrm{F}_{0}$ for intensity at zero chloride and $\mathrm{K}_{\mathrm{q}}$ for a quenching constant. By inserting each value of $\mathrm{F}_{\mathrm{a}}, \mathrm{F}_{0}$, and $\left[\mathrm{Cl}^{-}\right]_{\text {in }}$ into the formula, $\mathrm{Kq}$ at VNO neuronal cell body is calculated to be $8.79 \times 10^{-3} \mathrm{mM}^{-1}$ in wild type and $8.89 \times 10^{-3}$ $\mathrm{mM}^{-1}$ in TRPC2-/-. The relative values of MQAE fluorescence (normalized to $15 \mathrm{mM} \mathrm{Cl}^{-}$) measured in Tyrode solution and during urine application were averaged to extrapolate specific intracellular $\mathrm{Cl}^{-}$concentrations from the standard curve. 


\section{Abbreviations}

VNO: The vomeronasal organ; TRPC2: Transient receptor potential canonical channel 2; CACC: Calcium-activated chloride channels; CNG: Cyclic nucleotide gated; MQAE: N-[ethoxycarbonylmethyl]-6-methoxy-quinolinium bromide; mACSF: Mouse artificial cerebrospinal fluid.

\section{Authors' contributions}

SK participated in the design of the study, performed the imaging experiments, analyzed the data and helped draft the manuscript. LM maintained the supply of animals. JU and SM assisted with imaging experiments. CRY conceived of and supervised the study, and wrote the manuscript. All authors read and approved the final manuscript.

\section{Author details}

1 Stowers Institute for Medical Research, 1000 East 50th Street, Kansas City, MO 64110, USA. ${ }^{2}$ Department of Pharmacy, Institute of Pharmaceutical Science and Technology, Hanyang University, Seoul, Gyeonggi-do, Republic of Korea. ${ }^{3}$ Department of Anatomy and Cell Biology, University of Kansas Medical Center, Kansas City, KS 66160, USA.

\section{Acknowledgements}

We thank Andrea Moran and Lab Animal Services Facility for technical support. This work is supported by funding from Stowers Institute and the $\mathrm{NIH}$ (NIDCD 008003) to CRY and the Ministry of Science, ICT, and Future Planning of Korea (NRF-2013R1A1A1012884) to SSK. Original data underlying this manuscript can be accessed from the Stowers Original Data Repository at http://www.stowers.org/research/publications/libpb-691.

\section{Competing interests}

The authors declare that they have no competing interests.

Received: 4 July 2015 Accepted: 3 December 2015

Published online: 15 December 2015

\section{References}

1. Reuter D, Zierold K, Schroder WH, Frings S. A depolarizing chloride current contributes to chemoelectrical transduction in olfactory sensory neurons in situ. J Neurosci. 1998;18(17):6623-30.

2. Kaneko H, Putzier I, Frings S, Kaupp UB, Gensch T. Chloride accumulation in mammalian olfactory sensory neurons. J Neurosci. 2004;24(36):7931-8.

3. Kleene SJ, Gesteland RC. Calcium-activated chloride conductance in frog olfactory cilia. J Neurosci. 1991;11(11):3624-9.

4. Kleene SJ. Origin of the chloride current in olfactory transduction. Neuron. 1993;11(1):123-32.

5. Kurahashi T, Yau KW. Co-existence of cationic and chloride components in odorant-induced current of vertebrate olfactory receptor cells. Nature. 1993;363(6424):71-4.

6. Reisert J, Bauer PJ, Yau KW, Frings S. The Ca-activated Cl channel and its control in rat olfactory receptor neurons. J Gen Physiol. 2003;122(3):349-63.

7. Lowe G, Gold GH. Nonlinear amplification by calcium-dependent chloride channels in olfactory receptor cells. Nature. 1993;366(6452):283-6.

8. Pifferi S, Cenedese V, Menini A. Anoctamin 2/TMEM16B: a calciumactivated chloride channel in olfactory transduction. Exp Physiol. 2012;97(2):193-9.

9. Henkel B, Drose DR, Ackels T, Oberland S, Spehr M, Neuhaus EM. Coexpression of anoctamins in cilia of olfactory sensory neurons. Chem Senses. 2015;40(2):73-87.

10. Stephan AB, Shum EY, Hirsh S, Cygnar KD, Reisert J, Zhao H. ANO2 is the cilial calcium-activated chloride channel that may mediate olfactory amplification. Proc Natl Acad Sci USA. 2009;106(28):11776-81.

11. Amjad A, Hernandez-Clavijo A, Pifferi S, Maurya DK, Boccaccio A, Franzot J, Rock J, Menini A. Conditional knockout of TMEM16A/anoctamin1 abolishes the calcium-activated chloride current in mouse vomeronasal sensory neurons. J Gen Physiol. 2015;145(4):285-301.
12. Yang C, Delay RJ. Calcium-activated chloride current amplifies the response to urine in mouse vomeronasal sensory neurons. J Gen Physiol. 2010;135(1):3-13.

13. Kim S, Ma L, Yu CR. Requirement of calcium-activated chloride channels in the activation of mouse vomeronasal neurons. Nat Commun. 2011;2:365.

14. Kim S, Ma L, Jensen KL, Kim MM, Bond CT, Adelman JP, Yu CR. Paradoxical contribution of SK3 and GIRK channels to the activation of mouse vomeronasal organ. Nat Neurosci. 2012.

15. Kaneko H, Nakamura T, Lindemann B. Noninvasive measurement of chloride concentration in rat olfactory receptor cells with use of a fluorescent dye. Am J Physiol Cell Physiol. 2001;280(6):C1387-93.

16. Bevensee $\mathrm{MO}$, Weed RA, Boron WF. Intracellular $\mathrm{pH}$ regulation in cultured astrocytes from rat hippocampus. I. Role Of HCO3. J Gen Physiol. 1997; 110(4):453-65.

17. Funk K, Woitecki A, Franjic-Wurtz C, Gensch T, Mohrlen F, Frings S. Modulation of chloride homeostasis by inflammatory mediators in dorsal root ganglion neurons. Molecular pain. 2008;4:32.

18. Hille C, Lahn M, Lohmannsroben HG, Dosche C. Two-photon fluorescence lifetime imaging of intracellular chloride in cockroach salivary glands. Photochem Photobiol Sci. 2009;8(3):319-27.

19. He J, Ma L, Kim S, Schwartz J, Santilli M, Wood C, Durnin MH, Yu CR. Distinct signals conveyed by pheromone concentrations to the mouse vomeronasal organ. J Neurosci. 2010;30(22):7473-83.

20. Holy TE, Dulac C, Meister M. Responses of vomeronasal neurons to natural stimuli. Science. 2000;289(5484):1569-72.

21. Chen $\mathrm{H}$, Sun $\mathrm{D}$. The role of $\mathrm{Na}-\mathrm{K}-\mathrm{Cl}$ co-transporter in cerebral ischemia. Neurol Res. 2005;27(3):280-6.

22. Price TJ, Cervero F, de Koninck Y. Role of cation-chloride-cotransporters (CCC) in pain and hyperalgesia. Curr Top Med Chem. 2005;5(6):547-55.

23. DeFazio RA, Keros S, Quick MW, Hablitz JJ. Potassium-coupled chloride cotransport controls intracellular chloride in rat neocortical pyramidal neurons. J Neurosci. 2000;20(21):8069-76.

24. Chao AC, Dix JA, Sellers MC, Verkman AS. Fluorescence measurement of chloride transport in monolayer cultured cells. Mechanisms of chloride transport in fibroblasts. Biophys J. 1989;56(6):1071-81.

25. Ghiaroni V, Fieni F, Tirindelli R, Pietra P, Bigiani A. lon conductances in supporting cells isolated from the mouse vomeronasal organ. J Neurophysiol. 2003;89(1):118-27.

26. Liman ER. Regulation by voltage and adenine nucleotides of $\mathrm{C} \mathrm{Ca}^{2+}$ activated cation channel from hamster vomeronasal sensory neurons. J Physiol. 2003;548:777-87.

27. Dibattista M, Amjad A, Maurya DK, Sagheddu C, Montani G, Tirindelli R, Menini A. Calcium-activated chloride channels in the apical region of mouse vomeronasal sensory neurons. J Gen Physiol. 2012;140(1):3-15.

28. Klimmeck D, Daiber PC, Bruhl A, Baumann A, Frings S, Mohrlen F. Bestrophin 2: an anion channel associated with neurogenesis in chemosensory systems. J Comp Neurol. 2009;515(5):585-99.

29. Frings S, Reuter D, Kleene SJ. Neuronal Ca ${ }^{2+}$-activated $\mathrm{Cl}^{-}$channels-homing in on an elusive channel species. Prog Neurobiol. 2000;60(3):247-89.

30. Yu CR. Calcium imaging of vomeronasal organ response using slice preparations from transgenic mice expressing G-CaMP2. Methods Mol Biol. 2013;1068:211-20.

31. Ma L, Haga-Yamanaka S, Yu QE, Qiu Q, Kim S, Yu CR. Imaging neuronal responses in slice preparations of vomeronasal organ expressing a genetically encoded calcium sensor. J Vis Exp. 2011;(58).

32. He J, Ma L, Kim S, Nakai J, Yu CR. Encoding gender and individual information in the mouse vomeronasal organ. Science. 2008;320(5875):535-8. 